\title{
Implementasi Raspberry Pi 3 pada Sistem Pengontrol Lampu berbasis Raspbian Jessie
}

\author{
Rahmat Novrianda Dasmen ${ }^{\# 1}$, Rasmila ${ }^{* 2}$ \\ ${ }^{\#}$ Teknik Komputer, Universitas Bina Darma \\ JL. Jenderal A. Yani No. 3 Palembang \\ ${ }^{1}$ rahmat.novrianda.d@gmail.com \\ *Universitas Bina Darma \\ JL. Jenderal A. Yani No. 3 Palembang \\ ${ }^{2}$ rasmila@binadarma.ac.id
}

\begin{abstract}
Abstrak - Pada penelitian sebelumnya telah dihasilkan sistem pengontrol lampu menggunakan SMS gateway dengan bantuan perangkat mikrokontroler. Hal tersebut memberikan kemudahan manusia terhadap pengontrolan on/off lampu rumah, sehingga tidak perlu lagi repot untuk menekan saklar lampu yang berada di dinding rumah. Seiring dengan perkembangan teknologi, telah berkembang juga perangkat pengontrol, yaitu Raspberry $P i 3$ yang juga sering disebut sebagai mini Personal Computer (PC). Pada penelitian ini digunakan perangkat Raspberry Pi 3 untuk menerapkan Sistem Operasi Raspbian Jessie pada sistem pengontrol lampu serta menggunakan metode action research dalam memperoleh hasil penelitian sesuai dengan tujuan. Selain itu, dibutuhkan juga bahasa pemrograman phyton untuk dapat menjalankan user interface sistem pengontrol lampu berbasis Raspberry Pi 3. Pada pengujian sistem pengontrol lampu, digunakan lampu pijar senter dengan model fitting E10 dan lampu pijar rumah dengan model fitting E27. Hasil penelitian ini menunjukan bahwa Raspberry Pi 3 dengan Raspbian Jessie dibantu dengan perangkat modul relay dapat digunakan untuk mengontrol on/off lampu pijar rumah (model fitting E27) dengan mudah dan baik menggunakan user interface berbasis web.
\end{abstract}

Kata kunci - Sistem Pengontrol, Raspberry Pi 3, Raspbian Jessie, Phyton

\section{Pendahuluan}

Berdasarkan dari penelitian sebelumnya yang menjelaskan bahwa sistem pengendali lampu rumah manual (saklar pada dinding) dapat dipermudah dengan menerapkan SMS gateway untuk pengendalian on/off lampu rumah jarak jauh berbasis mikrokontoler [1]. Akan tetapi proses perakitan mikrokontroler dan konfigurasi SMS gateway sangat rumit dan tidak user friendly. Oleh karena itu, pada penelitian ini dilakukan penerapan Sistem Operasi Raspbian Jessie pada Sistem Pengontrol Lampu berbasis Raspberry Pi 3 sebagai salah satu kontribusi dalam pengembangan teknologi khususnya teknologi mobile, dikarenakan Perakitan serta Konfigurasi Raspberry Pi 3 yang sama seperti PC pada umumnya memudahkan siapapun untuk menerapkannya (user friendly). Sistem Pengontrol merupakan sistem atau peralatan yang digunakan user untuk mengontrol peralatan elektronik dari jarak jauh [2]. Raspbian Jessie adalah sistem operasi yang merupakan pengembangan sistem operasi Debian Jessie 8.0 yang dikhususkan untuk Raspberry Pi 3 dan digunakan untuk memproses seluruh fungsi sistem berbasis Raspberry Pi 3 [3]. Raspberry Pi 3 adalah suatu perangkat mini computer berukuran sebesar kartu kredit [4]. Raspberry Pi 3 (juga dikenal sebagai RasPi) adalah sebuah SBC (Single Board Computer) seukuran kartu kredit yang dikembangkan oleh Yayasan Raspberry Pi di Inggris (UK) [5]. Raspberry Pi dapat dimanfaatkan untuk pembuatan berbagai perangkat IoT yang dapat membantu automatisasi berbagai pekerjaan, seperti penerapan Raspberry Pi sebagai Wireless Access Point, Wifi Router hingga Server [6]. .. Pada penelitian ini akan dilakukan pengujian akhir dengan dua jenis bohlam yang berbeda, dimana perbedaan kedua bohlam ini terdapat pada tegangan listrik yang dibutuhkan dan juga tingkat hambatan yang ada pada filamen masing-masing bohlam. Filamen adalah kawat logam halus yang memiliki hambatan terhadap arus listrik yang lewat, dimana pada filamen energi listrik diubah menjadi panas dan bercahaya [7], dimana filamen ini memiliki hambatan yang dapat mengontrol arus listrik yang masuk agar sesuai dengan kebutuhan spesifikasi masing-masing bohlam. Oleh sebab itu, pada penelitian ini akan diketahui secara jelas jenis lampu mana yang lebih cocok digunakan pada sistem pengontrol lampu yang menggunakan perangkat kontol Raspberry Pi 3 dengan Raspbian Jessie serta dibantu dengan modul relay.

\section{Metodologi Penelitian}

\section{A. Metode Action Research}

Pada penelitian ini digunakan metode action research, yang merupakan salah satu bentuk rancangan penelitian. Pada metode action research, peneliti mendeskripsikan, menginterpretasi dan menjelaskan suatu kondisi pada saat 
yang bersamaan dengan melakukan intervensi dengan tujuan perbaikan ataupun partisipasi [8]. Metode action research terdiri dari beberapa tahapan yang dapat dilihat dari gambar di bawah ini [9]:

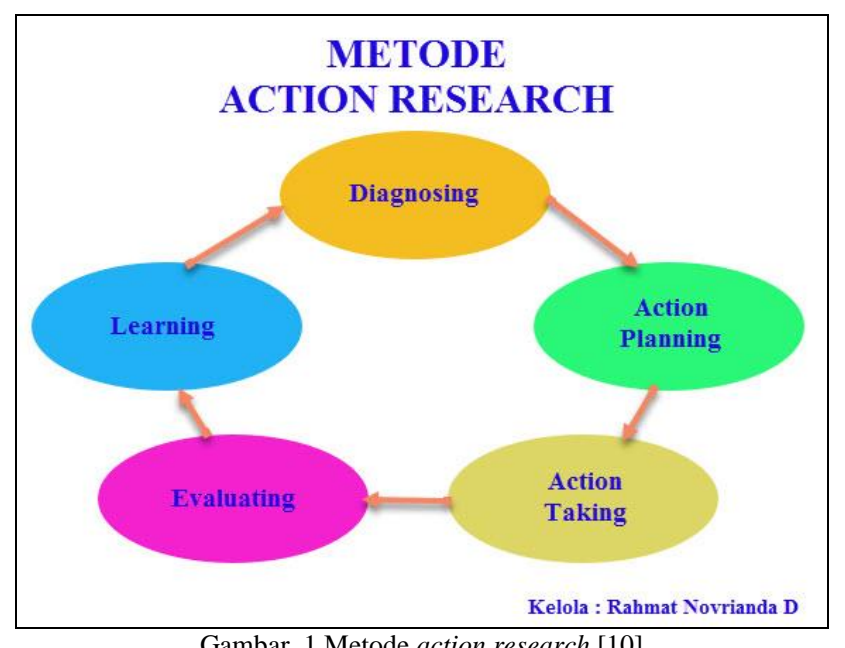

\section{Diagnosing}

Pada tahapan ini, dilakukan analisa terhadap pernasalahan yang terjadi, dimana permasalahan yang terjadi pada penelitian ini adalah mengembangkan teknologi terbaru dalam sistem pengontrol lampu jarak jauh dalam mendukung perkembangan teknologi.

\section{Action planning}

Action planning merupakan tahapan yang digunakan untuk merencanakan solusi yang dapat dilakukan agar dapat menyelesaikan permasalahan yang terjadi. Pada penelitian ini direncanakan untuk menerapkan sistem operasi Raspbian Jessie pada sistem pengontrol lampu berbasis Raspberry Pi 3. Pada penelitian ini, dibutuhkan beberapa perangkat keras lainnya agar dapat membangun sistem pengontrol lampu, yaitu modul relay, lampu pijar E10, lampu pijar E27, fitting lampu, kabel female to female dan kabel HDMI.

\section{Action taking}

Tahapan ini merupakan tahap pengambilan tindakan terhadap perencanaan yang telah dibuat. Oleh karena itu, pada penelitian ini dilakukan konfigurasi baik dari hardware (Raspberry $\mathrm{Pi} 3$ dan perangkat pendukung lainnya) hingga pada konfigurasi software (Raspbian Jessie dan Bahasa Pemrograman Phyton). Untuk dapat menjalankan user interface sistem pengontrol lampu, maka perlu dilakukan instalasi bahasa pemrograman phyton pada Raspberry Pi 3. User interface adalah bagian yang terpenting dari program komputer, karena proses komunikasi antara pengguna dengan sistem komputer dapat terjadi dengan adanya user interface [11]. Penelitian ini menggunakan bahasa pemrograman phyton, karena mudah dipelajari serta merupakan bahasa pemrograman yang power full, interpreter dan kepustakaan standar yang gratis [12]. Selain itu, Python juga dapat diterapkan untuk bermacam kebutuhan pengembangan software serta dapat dioperasikan pada bermacam platform sistem operasi [13]. Hal ini dilakukan guna membangun suatu sistem pengontrol lampu jarak jauh.

\section{Evaluating}

Pada tahapan ini, dilakukan pengujian terhadap sistem pengontrol lampu dengan menggunakan Lampu pijar senter (model fitting E10) dan Lampu pijar rumah (model fitting E40). Kedua jenis lampu ini akan dihubungkan ke rangkaian sistem pengontrol lampu berbasis Raspberry Pi 3 dengan bantuan modul relay kemudian rangkaian sistem pengontrol lampu tersebut dioperasikan. Dengan begitu, akan terlihat hasil lampu mana yang lebih cocok untuk digunakan pada rangkaian sistem pengontrol lampu berbasis Raspberry Pi 3 yang telah dibangun.

\section{Learning}

Dari hasil pengujian yang dilakukan pada tahap sebelumnya, dapat dipelajari tentang jenis lampu mana yang lebih baik digunakan pada sistem pengontrolan lampu berbasis Raspberry Pi 3.

\section{B. Perangkat yang dibutuhkan}

Adapun beberapa perangkat yang dibutuhkan pada penelitian ini adalah sebagai berikut:

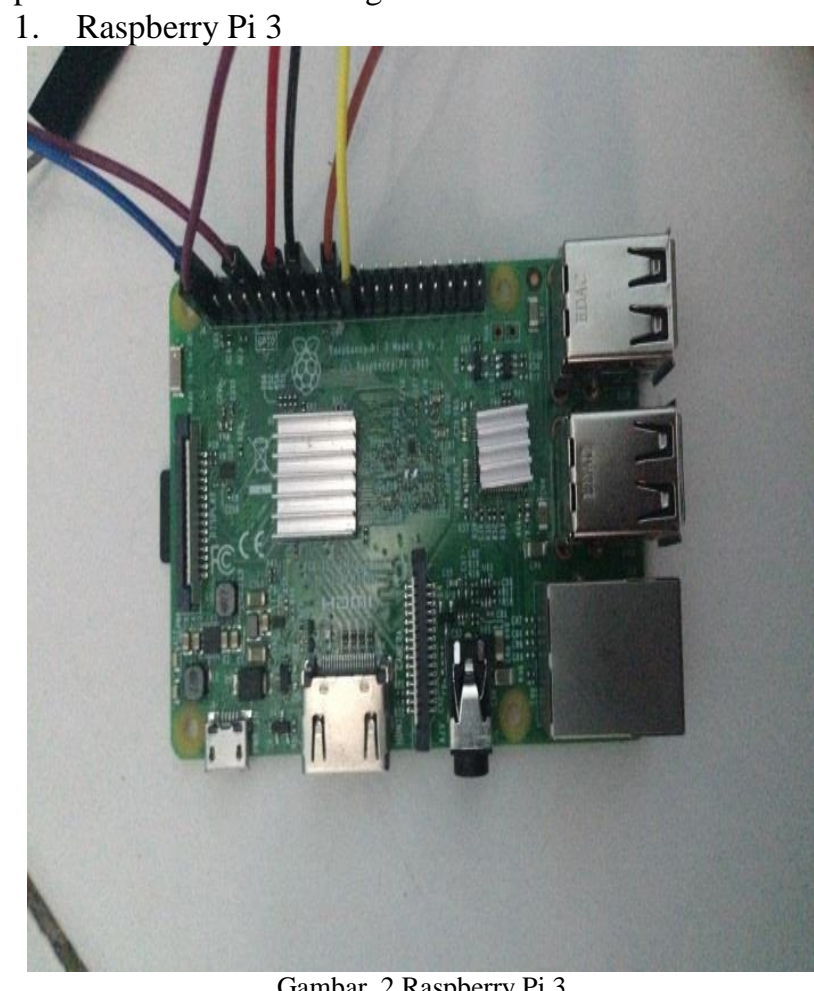

Gambar. 2 Raspberry Pi 3

Pada gambar 2 diatas, terlihat Raspberry Pi 3 yang memiliki processor dengan spesifikasi $700 \mathrm{MHz}$ ARM11 serta pada Raspberry Pi Model B memiliki RAM sebesar $512 \mathrm{MB}$, SD card sebagai media penyimpanannya, 2 port USB, konektor HDMI serta port ethernet [14]. 


\section{Modul Relay}

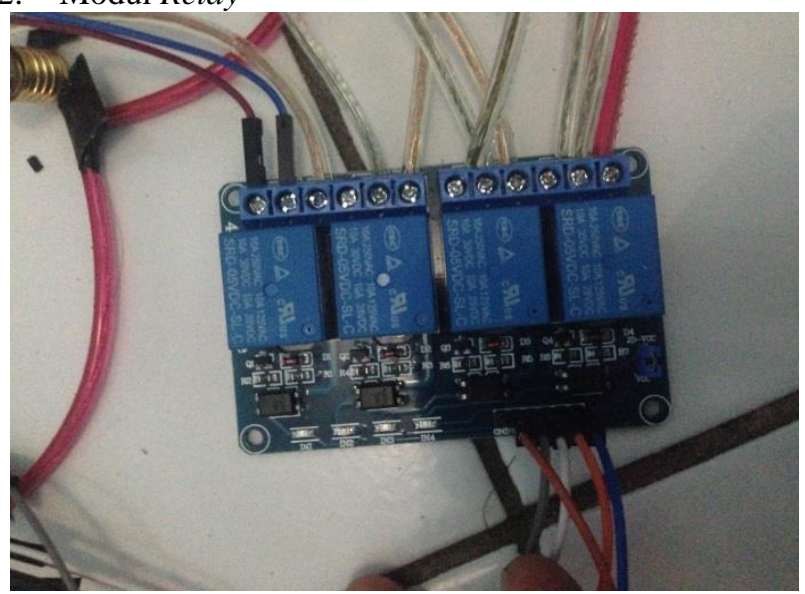

Gambar. 3 Modul Relay

Modul Relay yang digunakan adalah Modul Relay 4 Channel (dapat dilihat pada gambar 3 di atas), dimana relay merupakan komponen elektronika berupa saklar elektronik yang dikendalikan oleh arus listrik. Secara prinsip kerja, relay merupakan tuas saklar dengan lilitan kawat pada batang besi (solenoid) di dekatnya. Ketika solenoid dialiri arus listrik, tuas akan mendapat tarikan medan magnet yang dihasilkan dari solenoid sehingga kontak saklar akan menutup. Pada saat arus tidak diterima solenoid maka gaya magnet akan hilang, dan saklar akan kembali terbuka [15].

Selain itu, dibutuhkan juga beberapa perangkat keras (hardware) lainnya untuk mendukung dalam perakitan sistem pengontrol lampu menggunakan Raspberry Pi 3, dapat dilihat pada gambar 4 terdapat kabel female to female yang digunakan untuk menghubungkan Raspberry Pi 3 dengan modul relay. Kemudian pada gambar 5 dan gambar 6 berturut-turut terlihat 2 jenis bohlam (lampu pijar senter model fitting E10 dan lampu pijar rumah model fitting E27) yang digunakan pada pengujian sistem pengontrol lampu, yang bertujuan untuk mengetahui jenis bohlam mana yang lebih cocok dan tepat digunakan pada sistem pengontrol on/off lampu yang telah dikonfigurasi.

\section{Kabel Female to Female}

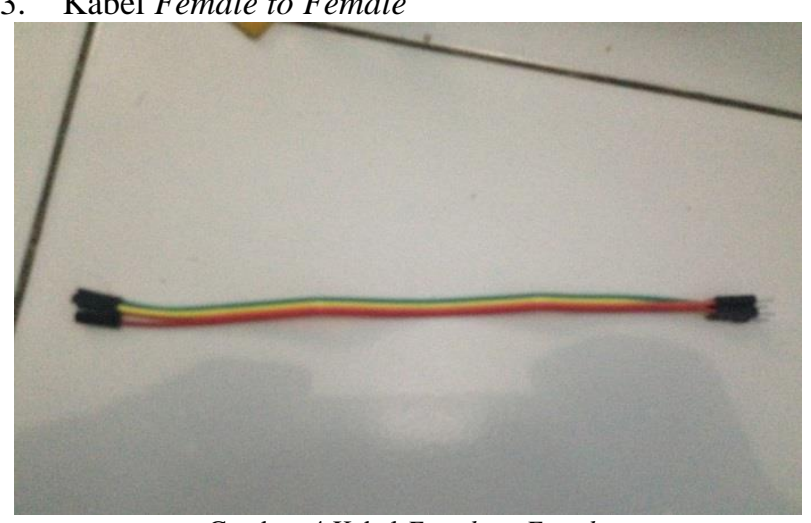

Gambar. 4 Kabel Female to Female
4. Lampu pijar senter (model fitting E10)

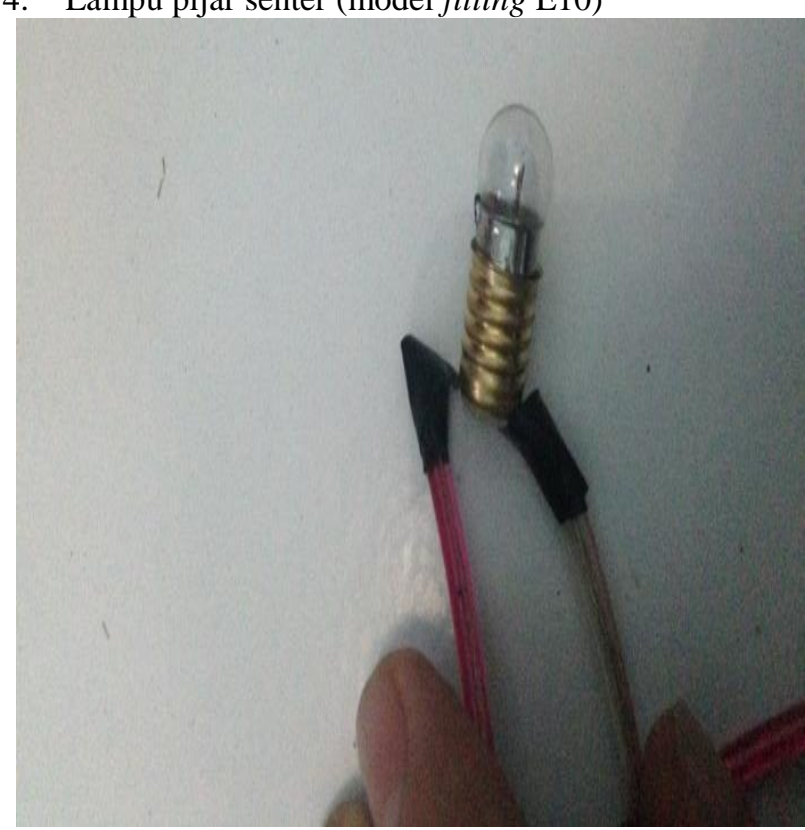

Gambar. 5 Lampu pijar senter (model fitting E10)

\section{Lampu pijar rumah (model fitting E27)}

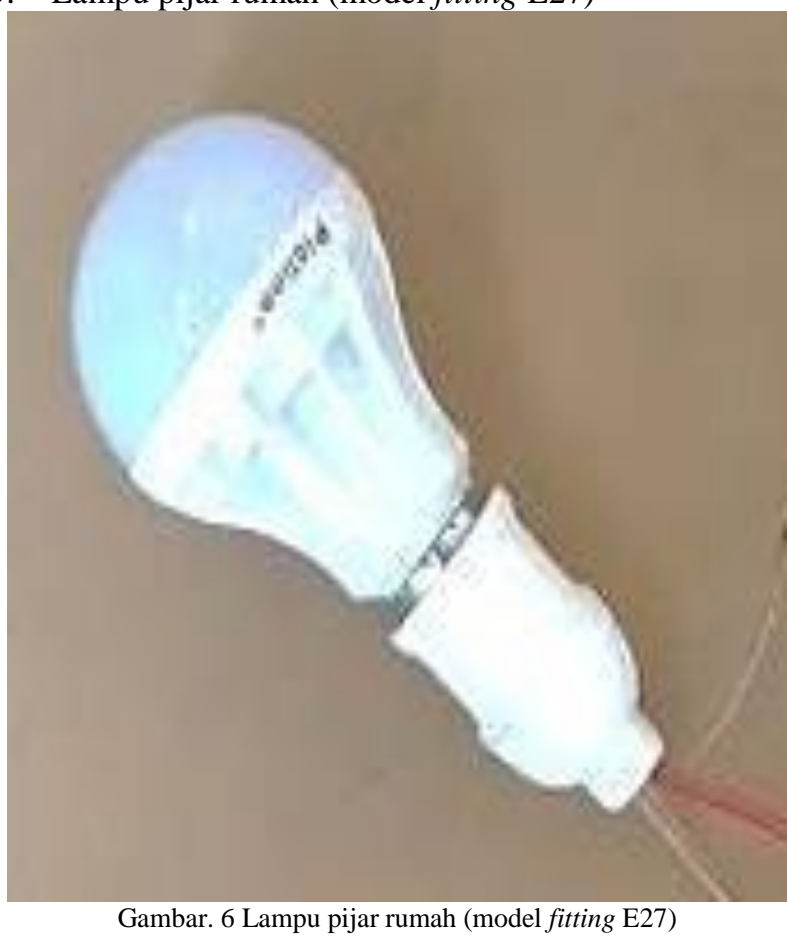

\section{Perakitan Perangkat}

Berikut ini adalah proses perakitan perangkat dimulai dari merakit Raspberry Pi 3 dengan Modul Relay 4 Channel, Perakitan 4 lampu ke Modul Relay 4 Channel hingga Perakitan Raspberry Pi 3 dengan Monitor (bisa juga digunakan TV LCD / TV LED yang dilengkapi dengan teknologi HDMI). Dapat dilihat pada gambar 7 di bawah ini merupakan skema perakitan sistem pengontrol lampu yang digunakan pada penelitian ini. 
1. Skema Wiring Sistem Pengontrol Lampu

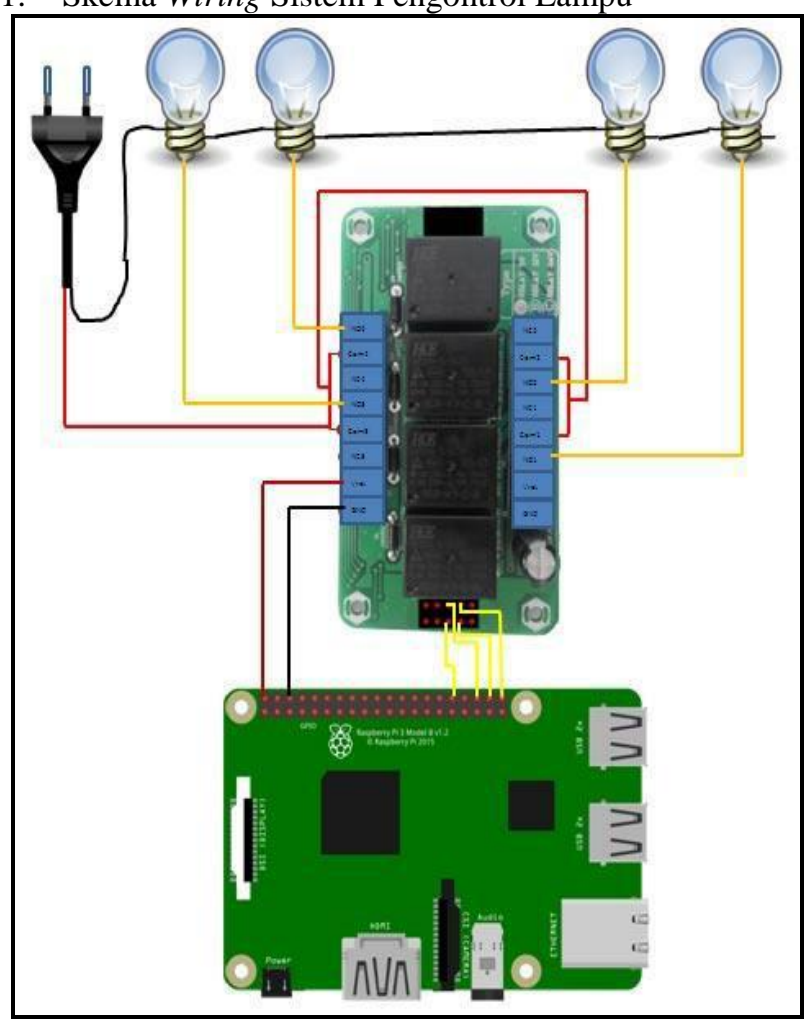

Gambar. 7 Skema Wiring Sistem Pengontrol Lampu

2. Perakitan Raspberry Pi 3 dengan Modul Relay

Skema pemasangan kabel female to female dari Raspberry Pi 3 ke Modul Relay 4 Channel dapat dilihat pada Tabel 1 di bawah ini:

TABEL I

SKEMA KABEL FEMALE TO FEMALE

\begin{tabular}{|c|c|c|}
\hline Raspberry Pi 3 & & Modul Relay \\
\hline BCM 12 & $\leftarrow \rightarrow$ & IN 1 \\
\hline BCM 16 & $\leftarrow \rightarrow$ & IN 2 \\
\hline BCM 20 & $\leftarrow \rightarrow$ & IN 3 \\
\hline BCM 21 & $\leftarrow \rightarrow$ & IN 4 \\
\hline
\end{tabular}

Gambar 8 di bawah ini merupakan hasil perakitan Raspberry Pi 3 dengan Modul Relay 4 Channel sesuai dengan skema pada tabel $1 \mathrm{di}$ atas:

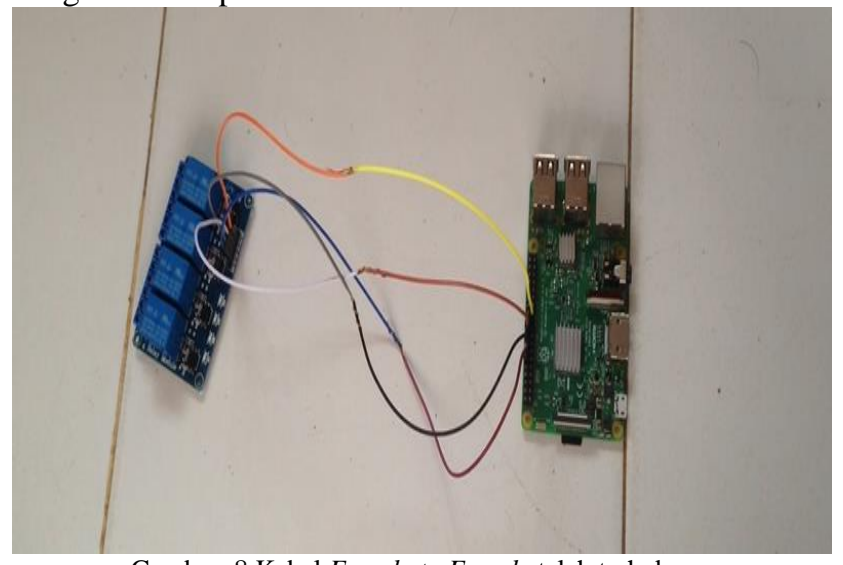

Gambar. 8 Kabel Female to Female telah terhubung
3. Perakitan Lampu Pijar E10 pada Modul Relay

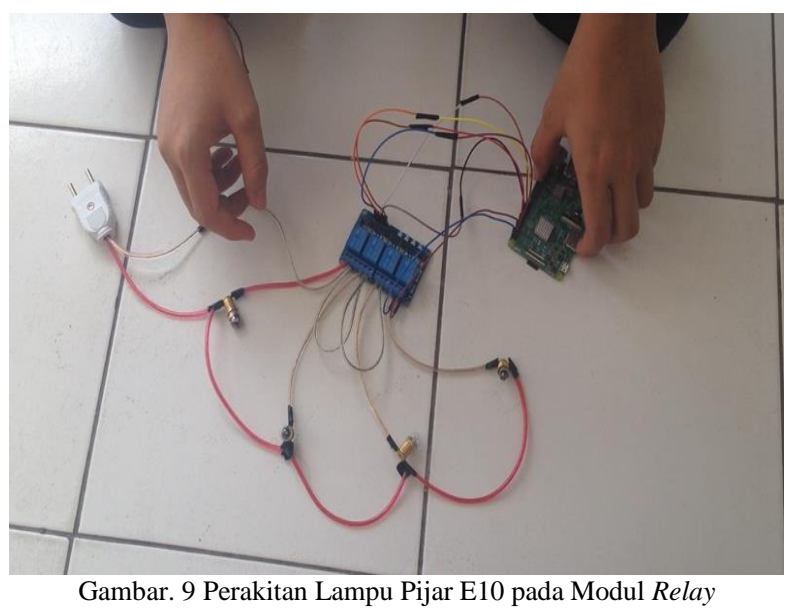

Pada gambar 9 di atas, terlihat bahwa keempat lampu pijar senter (model fitting E10) telah terhubung pada Modul Relay 4 Channel yang sebelumnya telah dihubungkan ke perangkat Raspberry Pi 3. Berikut ini penjelasan dari perakitan lampu pijar E10 ke Modul Relay 4 Channel:

a. Kabel lampu pertama dihubungkan pada channel 1 port 1 Modul Relay.

b. Kabel lampu kedua dihubungkan pada channel 2 port 1 Modul Relay.

c. Kabel lampu ketiga dihubungkan pada channel 3 port 1 Modul Relay.

d. Kabel lampu keempat dihubungkan pada channel 4 port 1 Modul Relay.

4. Perakitan Lampu Pijar E27 pada Modul Relay

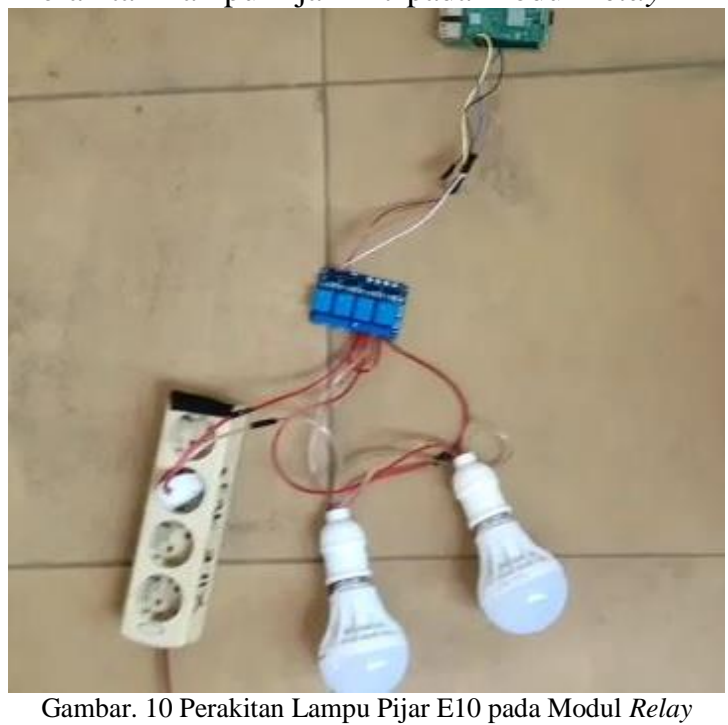

Proses perakitan lampu pijar E27 pada Modul Relay 4 Channel ini sama dengan perakitan lampu pijar E10 pada Modul Relay 4 Channel, tetapi pada pengujian ini hanya menggunakan dua lampu pijar E27. Seperti terlihat pada gambar 10 di atas. 
5. Perakitan Raspberry Pi 3 ke monitor

Modul Relay 4 Channel yang telah dihubungkan pada Perangkat Raspberry Pi 3 serta dihubungkan juga dengan Lampu Pijar, selanjutnya Perangkat Raspberry Pi 3 dihubungkan dengan monitor menggunakan kabel HDMI. Sebelum Raspberry Pi 3 dihubungkan ke monitor, terlebih dahulu Modul Relay 4 Channel dihubungkan dengan sumber listrik AC seperti terlihat pada gambar 11 di bawah ini:

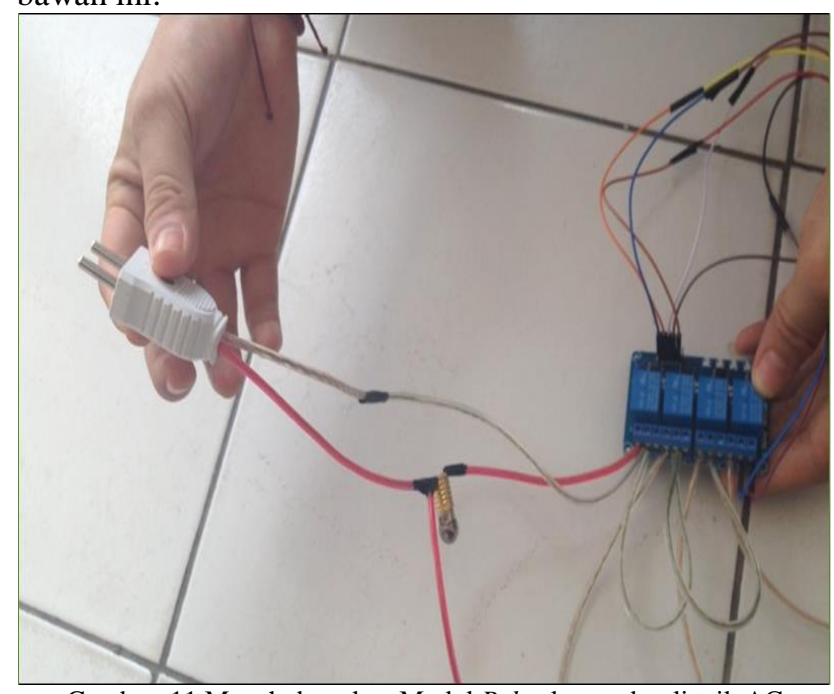

Gambar. 11 Menghubungkan Modul Relay ke sumber listrik AC

Setelah Modul Relay 4 Channel terhubung dengan sumber listrik AC, maka secara langsung Modul Relay 4 Channel dan Raspberry Pi 3 telah aktif. Selanjutnya Raspberry Pi 3 yang telah aktif ini dihubungkan ke monitor menggunakan kabel HDMI, seperti yang terlihat pada gambar 12 berikut ini:

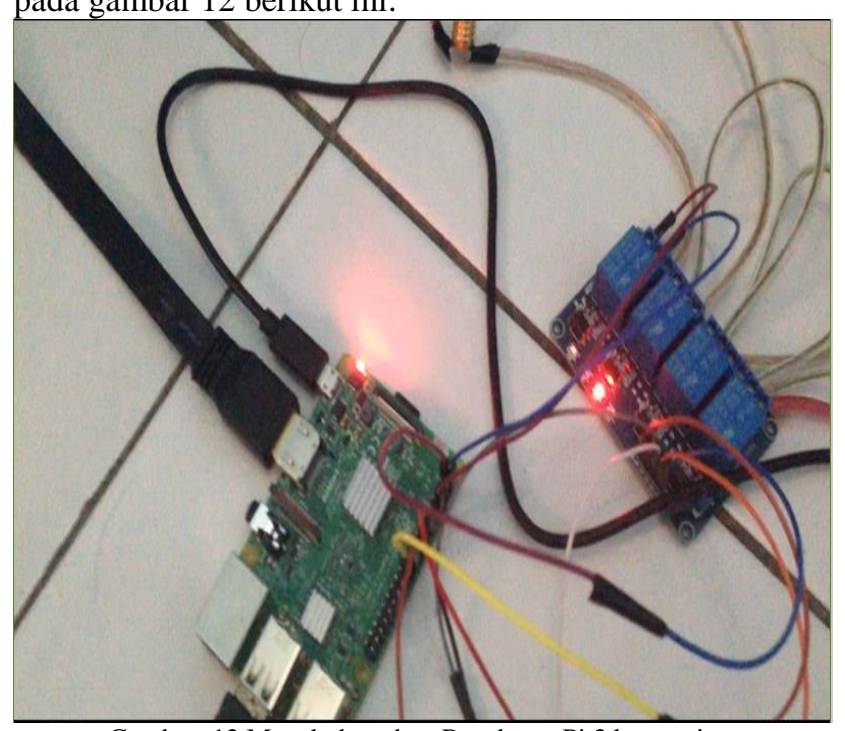

Gambar. 12 Menghubungkan Raspberry Pi 3 ke monitor

Agar dapat melakukan konfigurasi fitur-fitur pada Raspberry Pi 3, maka perlu dikoneksikan dengan jaringan internet. Berikut ini pada gambar 13 merupakan tampilan Raspberry Pi 3 yang telah terhubung dengan jaringan internet:

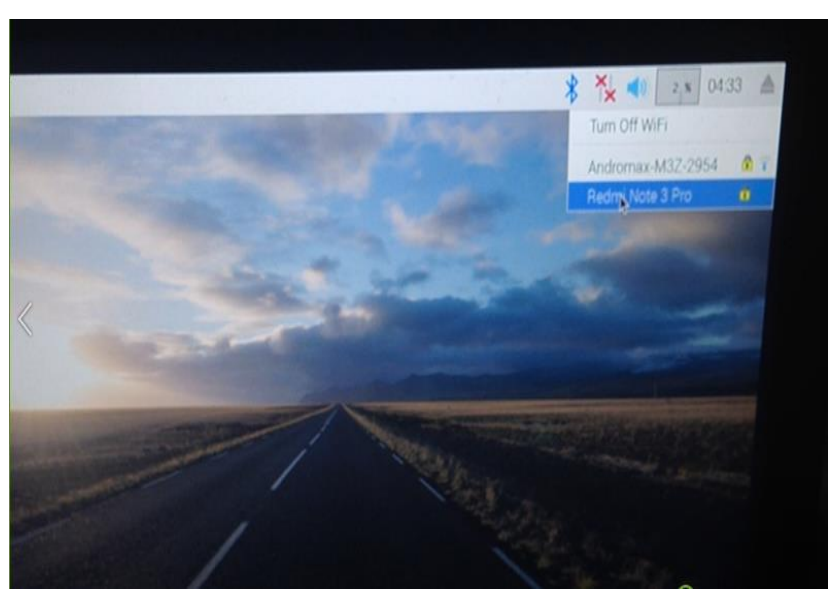

Gambar. 13 Menghubungkan Raspberry Pi 3 dengan jaringan internet

6. Konfigurasi Bahasa Pemrograman Phyton

Sebelum melakukan konfigurasi bahasa pemrograman phyton, tentunya sudah harus dipersiapkan SD card yang telah di-install Sistem Operasi Raspbian Jessie untuk dipasangkan pada perangkat Raspberry Pi 3. Setelah itu, pastikan bahwa Raspberry Pi 3 telah terkoneksi dengan jaringan internet. Proses pertama yang dilakukan adalah melakukan update serta upgrade fitur-fitur yang dimiliki oleh Raspbian Jessie, seperti pada gambar 14 dan gambar 15 berikut ini:

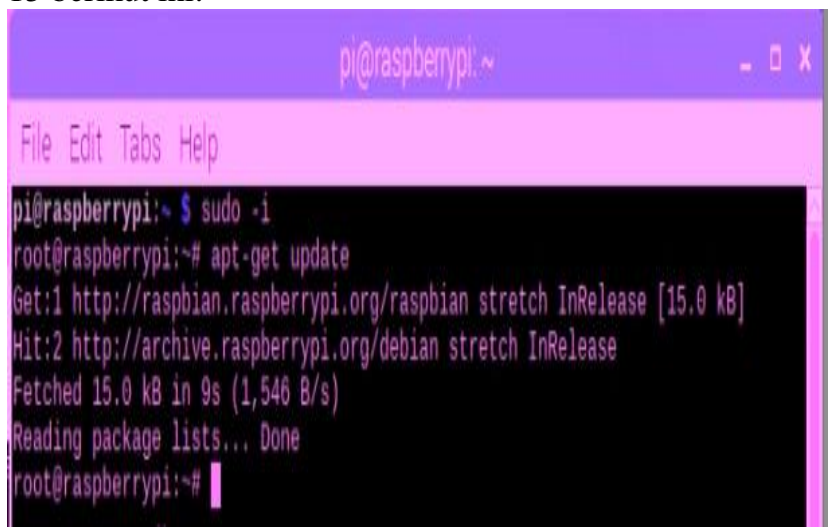

Gambar. 14 Proses Updete

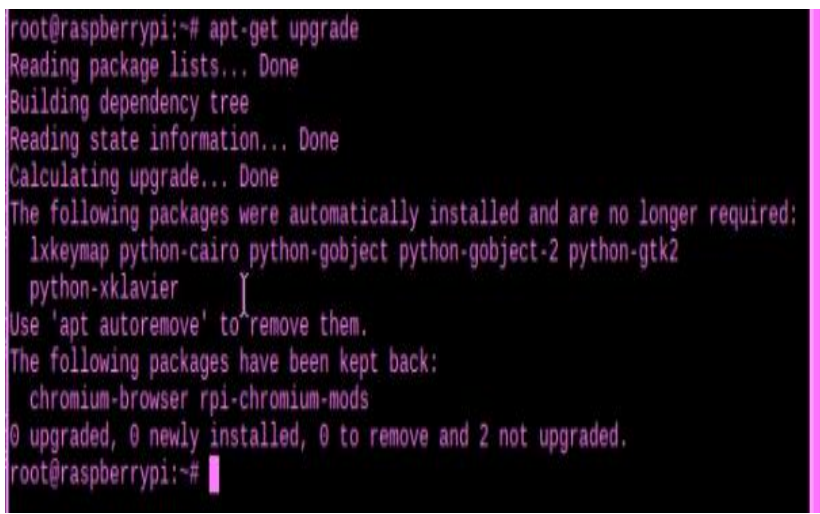

Gambar. 15 Proses Upgrade

Pada gambar 16 di bawah ini, terlihat proses download dan instalasi bahasa pemrograman phyton terhadap 
perangkat Raspberry Pi 3 yang digunakan pada penelitian ini:

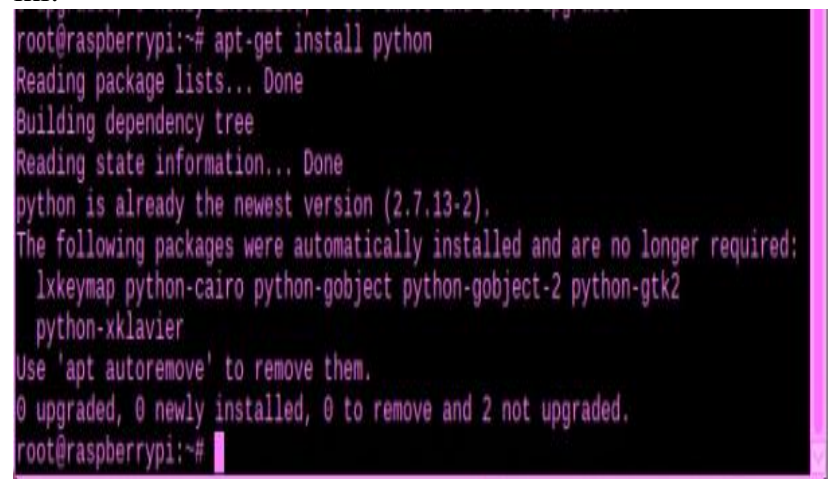

Gambar. 16 Proses download dan install bahasa pemrograman phyton

Setelah instalasi bahasa pemrograman phyton selesai, maka akan tampil seperi gambar 17 di bawah ini:

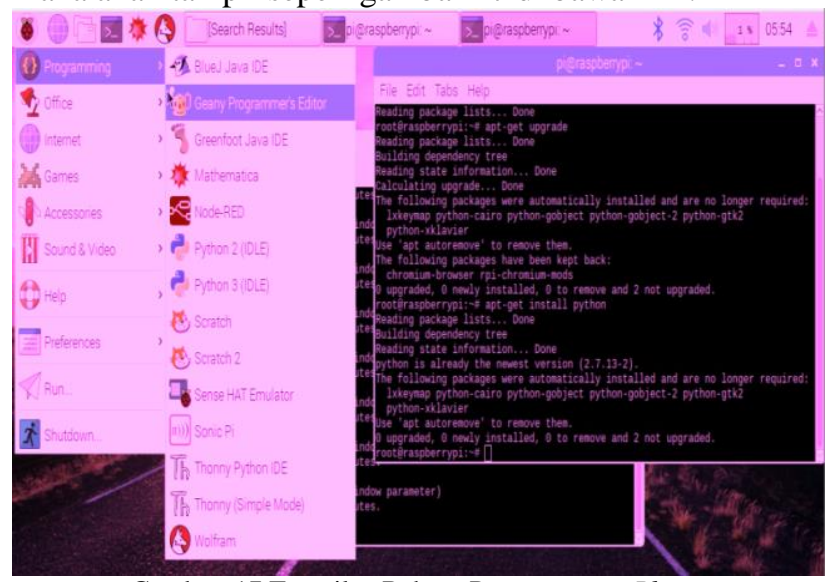

Gambar. 17 Tampilan Bahasa Pemrograman Phyton

Agar perangkat Raspberry Pi 3 dapat digunakan secara penuh, maka perlu dilakukan penambahan library rpi.gpio yang merupakan suatu library yang diperlukan untuk melakukan kontrol terhadap General Purpose Input Output (GPIO). Dapat dijelaskan bahwa GPIO pada Raspberry Pi 3 merupakan pin generik pada sirkuit terpadu (chip) yang perilakunya (termasuk apakah pin itu input atau output) dapat dikontrol (diprogram) oleh pengguna saat beroperasi [16]. Berikut ini proses penambahan fitur library rpi.gpio, dapat dilihat pada gambar 18 di bawah ini:

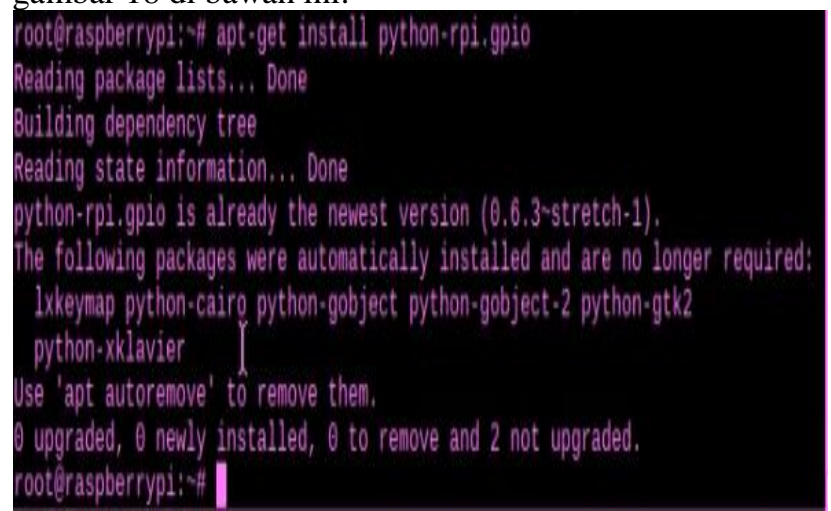

Gambar. 18 Proses Penambahan library rpi.gpio

\section{Menjalankan user interface}

Sebelum menjalankan user interface pada Raspberry Pi 3 , tentunya user interface yang dibangun menggunakan bahasa pemrograman phyton tersebut sudah harus terdaftar pada hosting online . Hal ini dilakukan agar nanti user interface yang telah online dapat terdeteksi oleh perangkat Raspberry Pi 3 yang juga telah terkoneksi dengan jaringan internet. Setelah selesai proses konfigurasi hosting online, maka pada folder website yang terdapat pada bahasa pemrograman phyton akan ditemukan file dengan nama "IOTraspi.py". File ini harus di-copy pada directory "/home/pi" dan selanjutnya buka file tersebut menggunakan perintah pada gambar 19 berikut ini:

sudo nano IOTraspi.py

Gambar. 19 Perintah untuk membuka file IOTraspi.py

Setelah file "IOTraspi.py" terbuka, maka akan tampil seperti pada gambar 20. Agar dapat menjalankan user interface yang telah dipersiapkan dan telah di-hosting online, maka perlu dilakukan perubahan terhadap alamat_website menjadi http://iotraspberry.pe.hu, dimana alamat website ini merupakan alamat dari user interface yang telah terdaftar pada hosting online, seperti yang terlihat pada gambar 21 di bawah ini:

url = ,alamat_website/IOTraspi.txt'

$$
\text { Gambar. } 20 \text { Isi dari file IOTraspi.py }
$$

url = „http://iotraspberry.pe.hu/IOTraspi.txt'

Gambar. 21 Perubahan alamat website menjadi http://iotraspberry.pe.hu

Setelah proses konfigurasi di atas selesai dilakukan, maka file "IOTraspi.py" dapat disimpan serta ditutup. Untuk dapat mengetahui bahwa konfigurasi yang dilakukan telah benar dan user interface untuk sistem pengontrolan lampu dapat dijalankan, maka perlu dijalankan program phyton dengan perintah pada gambar 22 berikut ini:

Sudo python IOTraspi.py

Gambar. 22 Perintah untuk menjalankan program phyton

Pastikan tidak terjadi error dalam menjalankan program phyton. Apabila proses menjalankan program phyton berhasil, maka user interface yang telah dipersiapkan untuk sistem pengontrol akan tampil seperti pada gambar 23 di bawah ini:

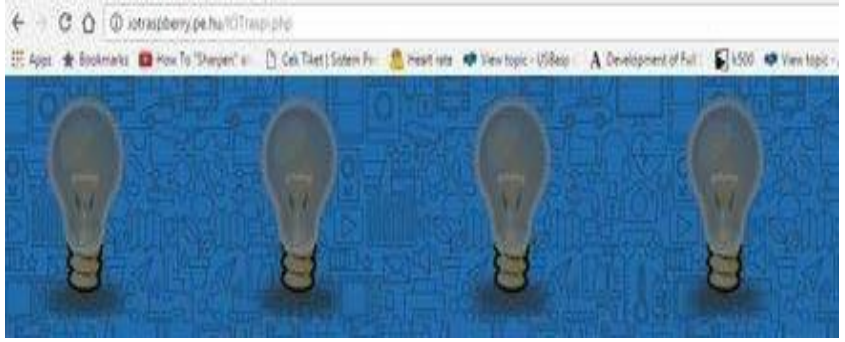

Gambar. 23 User Interface Sistem Pengontrol Lampu 


\section{HASIL DAN PEMBAHASAN}

\section{A. Hasil}

Dari penelitian yang telah dilakukan diperoleh hasil dari pengujian sistem pengontrol lampu yang menggunakan lampu pijar senter (model fitting E10) dan lampu pijar rumah (model fitting E27). Dalam pengujian menggunakan 4 (empat) lampu pijar E10, sistem pengontrol lampu tidak berjalan dengan baik dikarenakan satu per satu lampu pijar E10 rusak hingga meledak.

Oleh karena itu, pengujian langsung dilanjutkan menggunakan 2 (dua) lampu pijar E27, dimana sistem pengontrol lampu dapat berjalan dengan baik dan dapat dilihat pada gambar-gambar di bawah ini yang merupakan hasil dari pengujiannya. Berikut ini merupakan proses menghidupkan (on) satu lampu pijar E27 manggunakan user interface dari sistem pengontrol lampu, dapat dilihat pada gambar 24 di bawah ini

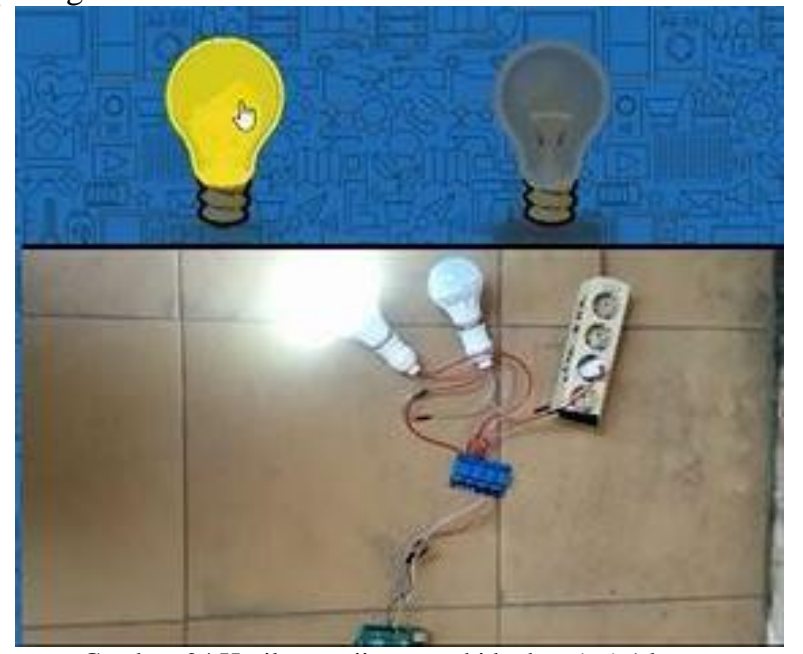

Gambar. 24 Hasil pengujian menghidupkan (on) 1 lampu

Lampu yang pertama (sebelah kiri) dapat hidup hanya dengan menekan icon lampu yang terdapat pada user interface sistem pengontrol lampu. Selanjutnya dapat dilihat pada gambar 25 jika icon lampu kedua (sebelah kanan) pada user interface sistem pengontrol lampu ditekan / klik:

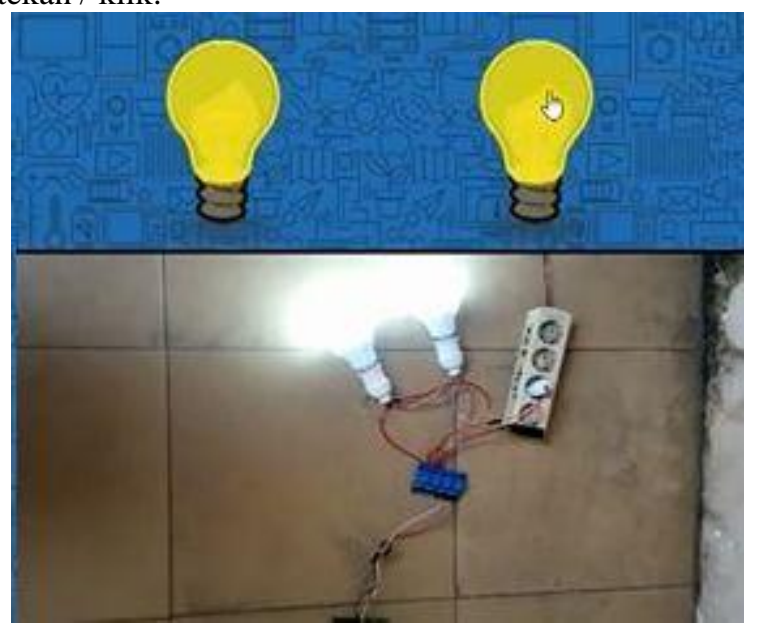

Gambar. 25 Hasil pengujian menghidupkan (on) 2 lampu
Untuk dapat mematikan (off) lampu pijar E27 tersebut, maka dapat dilakukan dengan cara menekan / klik icon lampu mana yang akan dimatikan (off) pada user interface sistem pengontrol lampu.

\section{B. Pembahasan}

Dari hasil pengujian yang telah dilakukan pada penelitian ini, diketahui bahwa kegagalan pada pengujian terhadap lampu pijar senter (model fitting E10) yang mengakibatkan keempat lampu pijar E10 rusak (meledak) adalah karena tegangan listrik (voltage) sumber listrik AC tidak sesuai dengan spesifikasi yang dibutuhkan oleh lampu pijar senter (model fitting E10) serta hambatan yang dimiliki oleh filamen lampu pijar E10 tidak mampu menahan arus listrik yang melaluinya sehingga filamen rusak hingga membuat lampu pijar E10 meledak.

Pada pengujian selanjutnya yang menggunakan lampu pijar rumah (model fitting E27), dimana sistem pengontrol lampu berjalan dengan baik. Hal ini dikarenakan lampu pijar E27 membutuhkan spesifikasi yang sesuai dengan sumber listrik AC serta hambatan pada filamennya juga mampu menahan arus yang lewat sehingga filamen menghasilkan cahaya yang cukup untuk menjadi penerangan (seperti fungsi lampu pada umunya). Selain itu, konfigurasi Raspberry Pi 3 hingga user interface juga telah dilakukan dengan baik sehingga Sistem Pengontrol Lampu menggunakan Raspberry Pi 3 berbasis Raspbian Jessie dapat berjalan sesuai dengan tujuan

\section{KESIMPULAN}

Dari penelitian yang telah dilakukan, maka dapat disimpulkan bahwa Sistem Pengontrol Lampu juga dapat dibangun dengan menggunakan perangkat Raspberry Pi 3 yang memiliki Sistem Operasi Raspbian Jessie. Perangkat Raspberry Pi 3 ini dibantu oleh Modul Relay 4 Channel yang fungsinya untuk mengontrol aliran arus listrik ke lampu pijar yang digunakan, dengan kata lain Modul Relay 4 Channel bertindak sebagai saklar. User interface yang dipergunakan pada Sistem Pengontrol Lampu dibangun menggunakan bahasa pemrograman phyton serta didaftarkan ke hosting online, sehingga Raspberry Pi 3 dengan User Interface dapat terhubung secara online memanfaatkan jaringan internet. Dari hasil pengujian yang telah dilakukan pada penelitian ini, dapat disimpulkan juga bahwa rangkaian Sistem Pengontrol Lampu berbasis Raspberry Pi 3 yang dihasilkan pada penelitian ini hanya cocok untuk jenis Lampu Pijar Rumah (model fitting E27) dan tidak cocok untuk Lampu Pijar Senter (model fitting E10). Hal ini dikarenakan spesifikasi tegangan listrik yang digunakan pada Sistem Pengontol Lampu tersebut hanya sesuai dengan spesifikasi tegangan listrik yang dibutuhkan lampu pijar E27 sehingga filamen lampu pijar E27 mampu mengalirkan arus listik dengan baik serta dapat menciptakan cahaya penerangan. Oleh karena itu, untuk peneliti selanjutnya dapat mengembangkan agar sistem pengontrol lampu berbasis Raspberry Pi 3 dengan Sistem Operasi Raspbian Jessie ini tidak hanya terbatas pada kontrol lampu pijar 
E27 tetapi juga dapat digunakan untuk mengontrol berbagai jenis alat elektronika lainnya dalam kehidupan sehari-hari

\section{REFERENSI}

[1] R. Novrianda, "Implementasi SMS Gateway pada Sistem Pengendali Lampu Ruangan berbasis Mikrokontroler," $J$. Maklumatika, vol. 3, no. 2, pp. 130-139, 2017.

[2] E. Priyono, "Pesawat Terbang Tanpa Awak (PTTA) sebagai Salah Satu Komponen Kekuatan Udara," J. Ind. Elektro dan Penerbangan, vol. 1, no. 2, 2018

[3] W. Ladita and H. Arie Pradana, "Konfigurasi Smart TV menggunakan Raspberry $\mathrm{Pi}$ berbasis Linux Debian," $J$. SISFOKOM, vol. 4, no. 1, pp. 34-40, 2015.

[4] E. Fernando, "Automatisasi Smart Home Dengan Raspberry Pi Dan Smartphone Android," in Konferensi Nasional Ilmu Komputer (KONIK) 5, 2014.

[5] R. N. Dasmen and R. M. N. Halim, "Implementasi Papan Informasi Digital menggunakan Raspberry Pi 3 pada STIPER Sriwigama Palembang," Comput. J. Comput. Sci. Inf. Syst., vol. 2, no. 2, pp. 196-206, 2018

[6] E. Susanti and J. Triyono, "Prototype Alat IoT (Internet of Things) untuk Pengendali dan Pemantau Kendaraan secara Realtime," in Simposium Nasional RAPI XV 2016, 2016, pp. 401-407.

[7] B. B. Agam, Yushardi, and T. Prihandono, "Pengaruh Jenis dan Bentuk Lampu terhadap Intensitas Pencahayaan dan Energi Buangan melalui Perhitungan Nilai Efikasi Luminus," J. Pendidik. Fis., vol. 3, no. 4, pp. 384-389, 2015.

[8] R. N. Dasmen, "Implementasi Metode VLSM (Variable Length
Subnet Mask) pada Pemetaan IP Address LAN (Local Area Network) STIPER Sriwigama Palembang," Comput. J. Comput. Sci. Inf. Syst., vol. 2, no. 2, pp. 112-118, 2018.

[9] R. M. Davison and M. G. Martinsons, "Principles of Canonical Action Research," Info Syst. J., vol. 14, pp. 65-86, 2004.

[10] R. N. Dasmen, "Implementasi Raspberry Pi 3 sebagai Wireless Access Point pada STIPER Sriwigama Palembang," J. Inform. J. Pengemb. IT, vol. 3, no. 3, pp. 387-393, 2018.

[11] R. Y. Arindiono and N. Ramadhani, "Perancangan Media Pembelajaran Interaktif Matematika untuk Siswa Kelas 5 SD," $J$. Sains dan Seni POMITS, vol. 2, no. 1, 2013.

[12] G. S. Kuncoro and Martanto, "Penampil Informasi Jarak Jauh dengan Masukan Teks dari Keyboard berbasis Raspberry Pi," in Prosiding Seminar Nasional XI ReTII, 2017, pp. 45-51.

[13] T. R. Perkasa, H. Widyantara, and P. Susanto, "Rancang Bangun Pendeteksi Gerak menggunakan Metode Image Subtraction pada Single Board Computer (SBC)," J. JCONES, vol. 3, no. 2, 2014.

[14] M. Richardson and S. Wallace, Getting started with raspberry PI. Sebastopol, California: O’Reilly Media, Inc, 2012.

[15] S. K. Dewi, R. D. Nyoto, and E. D. Marindani, "Perancangan Prototipe Sistem Kontrol Suhu dan Kelembaban pada Gedung Walet dengan Mikrokontroler berbasis Mobile," JEPIN (Jurnal Edukasi dan Penelit. Inform., vol. 4, no. 1, pp. 36-42, 2018.

[16] N. Herlambang, M. Pujiantara, and A. Priyadi, "Pemodelan Kurva Karakteristik Inverse Non-Standar Pada Rele Arus Lebih Digital dengan Metode Interpolasi Lagrange," J. Tek. ITS, vol. 5, no. 2, 2016. 